\title{
Research on Exploratory Factor Analysis (EFA) of the Efficiency of Economic Responsibility Audit of Off-post Cadres in Internal Audit
}

\author{
Xing $\mathrm{Li}^{1, \mathrm{a}}$, Jianmin $\mathrm{He}^{1, \mathrm{c}}$ and Sheng Zhao ${ }^{2, \mathrm{~b}}$ \\ ${ }^{1}$ College of Economy and Management,LongDong University ,QingYang City,Gansu \\ ${ }^{2}$ Project finance department,LongDong University ,QingYang City,Gansu \\ aleebj@189.cn, ${ }^{\mathrm{b}} 231688629 @ q q . c o m,{ }^{c}$ 58360278@qq.com
}

Keywords: Internal audit, AMOS, Audit, Economic responsibility audit, Efficiency

\begin{abstract}
Different circumstances and impact of a variety of factors in the actual operation of economic responsibility audit of off-post cadres in internal audit, a structural equation model was established to improve the efficiency of economic responsibility audit of off-post cadres and by observing the links in improving the efficiency observed variables between the links were selected in order to build a measurement model; AMOS software was applied for analysis of survey data, so that the roadmap of the measurement model was obtained, which showed that four links of audit focus, standard audit system, audit feedback mechanism and auditors' professional quality had the biggest impact on efficiency of economic responsibility audit in internal audit and thus were the priorities in improving economic responsibility audit of internal audit.
\end{abstract}

\section{Introduction}

Since carrying out the economic responsibility audit of off-post cadres in administrative departments, enterprises and institutions, the Chinese government has been organically combining administrative means to manage the cadres and business means to supervise cadres, so that all economic management activities of cadres are put under supervision, which plays a positive role in further promoting administrative cadres' integrity and self-discipline, sense of responsibility and risk awareness, and level of management and also provides an important reference for the party and government departments and organizations in selecting, appointing or dismissing cadres. However, in view of the current practice of audit on off-post cadres, there are still serious limitations, of which poor audit quality and efficiency is more prominent.

With government departments attaching increasingly greater importance to audit of off-post cadres, the research of audit efficiency becomes a great concern. Therefore, this article tried to build a multi-factor structural model on the audit efficiency of economic responsibility audit of off-post cadres in internal audit. Using AMOS software that can provide a graphical environment for each step in the construction of the structural equation model, this article rapidly built a model to test how the variables affect each other and why such impact will occur. The purpose was by establishing AMOS model and using its roadmap to discuss, analyze and verify the audit efficiency of economic responsibility audit on off-post cadres so as to identify the main causes of inefficient internal audit and provide reference for enhancing the efficiency of internal audit.

\section{Definition of Internal Auditing Efficiency}

Internal audit is an independent review and evaluation by an entity's specialized internal audit departments and personnel on the entity's financial results and economic activities, and the audit results shall be reported to the main person in charge of the entity. Such audit is significantly characterized by constructiveness and introverted service, which aims to help the entity to improve internal control, management, and economic efficiency. In Western countries, internal audit is generally considered the eyes and ears, assistant and consultant of an enterprise's general manager. In 1999, the Institute of Internal Auditors (IIA) Council adopted a new definition of internal audit, saying 
"internal audit is an independent and objective assurance and consulting service, aiming to add value and improve operation, which by systematic and standard means assesses risks, improves risk control and organizational governance structure in order to achieve the established goals of the organization." Audit efficiency refers to the ratio relations between audit costs incurred in the audit practice and audit results as an important indicator for audit institutions to strengthen internal management, reduce audit risk and improve audit quality.

\section{Research Methods and Data Processing Research Methods}

Audit efficiency has long been an issue discussed and studied by many scholars. Relevant literatures have proposed valuable views and methods to improve the efficiency, but by reviewing the relevant literatures, the article found there is a lack of more quantitative studies on analysis of the audit efficiency. Along with analysis by mathematical vector model increasingly maturing, this article attempted to demonstrate factors that affect the efficiency of economic responsibility audit of off-post cadres by AOMS roadmap and establishing a structural equation model (SEM) and a measurement equation model. A structural model refers to the relationship between the latent variables, as well as unexplained variance of other variables in the model. A measurement model describes how the latent variable are measured and conceptualized by corresponding explicit indicators. The model contained three types of variables: observed variables, latent variables and error variables. There were four latent variables: audit focus, standard audit system, audit feedback mechanism and auditors' professional quality. These variables were difficult to measure directly, so they were called latent variables. Observed variables are measurable variable used to reflect the latent variables. See the observed variables selected in Table 1. Error variables refer to biases arising from measuring the observed variables and ignoring secondary observed variables and so on.

Table 1. Observation variables table.

\begin{tabular}{|c|c|}
\hline Independent variable & Dependent variable \\
\hline Audit Focus & $\begin{array}{l}\text { Key data. } \\
\text { Reflect the problem of audit. } \\
\text { Sector focus. } \quad \text { High risk business }\end{array}$ \\
\hline $\begin{array}{c}\text { Standard } \\
\text { audit system }\end{array}$ & $\begin{array}{c}\text { Audit pass lead time, Establishment of different audit system, } \\
\text { Any of the audit time division }\end{array}$ \\
\hline Audit and feedback mechanism & $\begin{array}{l}\text { Pay attention to the audit conclusion. Tracking audit } \\
\text { mechanism of internal audit effectively establishment of audit archives }\end{array}$ \\
\hline $\begin{array}{c}\text { Auditors } \\
\text { quality }\end{array}$ & $\begin{array}{c}\text { Service quality. Financial foundation. internal control system.. Continuing } \\
\text { Education }\end{array}$ \\
\hline
\end{tabular}

\section{Structure Model}

Represented exogenous latent variables, internal latent variables, e disturbance variables, and path coefficients, as shown in Fig .1. The regression equation between latent variables in Fig .1 was:

$\eta=\lambda_{1.1+} \xi_{1}+\lambda_{1.2+} \xi_{2}+\lambda_{1.3+} \xi_{3}+\lambda_{1.4+} \xi_{4}+e$ 


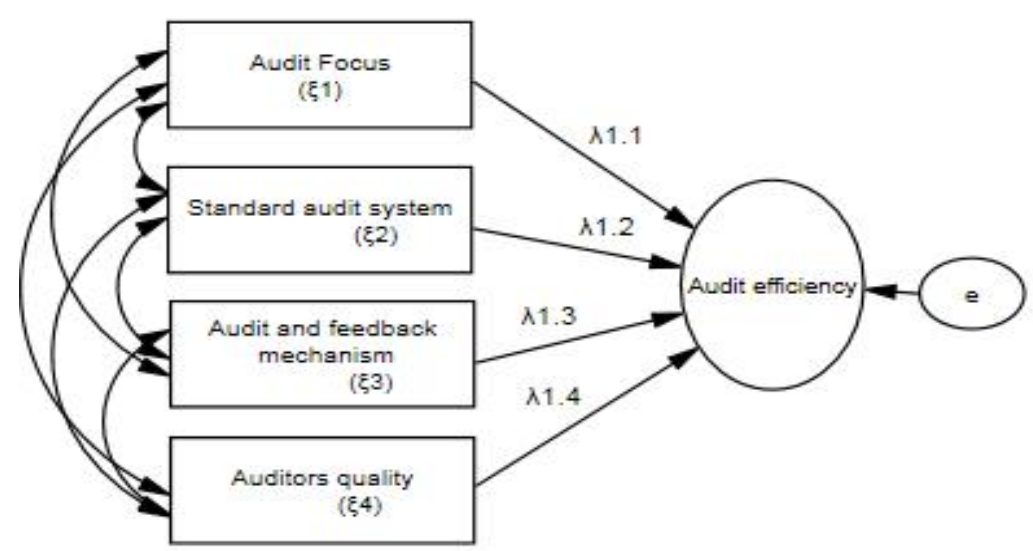

Figure 1. Measurement Model

Economic responsibility audit of off-post cadres was taken as an example to introduce the measurement model as shown in Fig .2. $\xi$ represented latent variables, $X$ observed variables, e errors, and $\lambda$ path coefficients, so that the regression equation between observed variables and latent variables was:

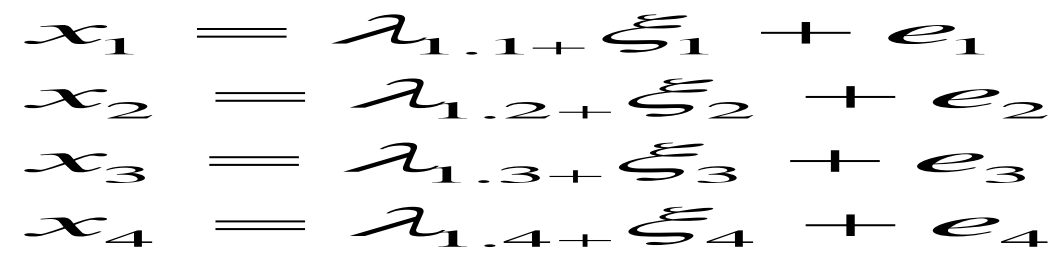

The matrix equation of the regression equation was expressed as:

$X=\Lambda_{x} \xi+\delta$

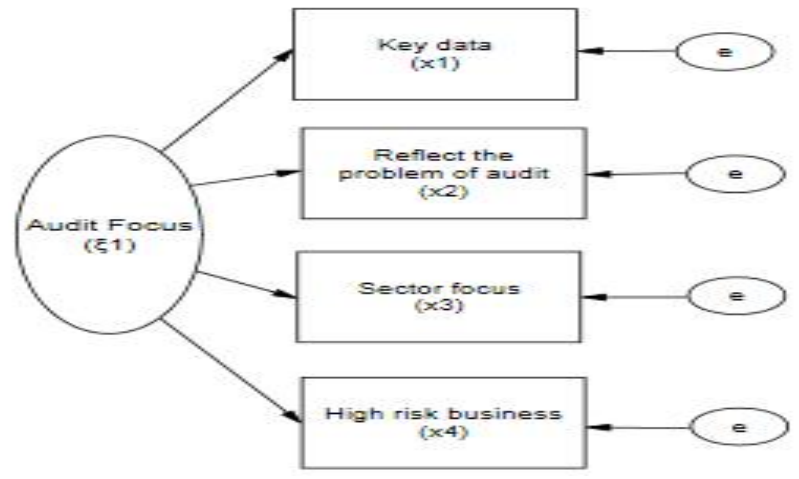

Figure 2. Estimation method formodel

AMOS stands for Analysis of Moment Structures that can verify all kinds of measurement models and different path analysis models; or can be used for multi-group analysis and inspection of structured means, selection of the optimal model among multiple competing models or alternative models for single or multiple groups. With the inclusion of AMOS into SPSS family, it is being used more and more extensively. Moment structures with similar connotation to covariance matrixes are suitable for the analysis of structural equation modeling (SEM), which is also known as analysis of covariance structures or analysis of causal models.

\section{Data Collection and Processing}

This survey distributed 350 copies of questionnaire to audit workers with business units that implement internal economic responsibility audit. Data of valid copies of questionnaire obtained from 
the survey were analyzed. The total number of valid copies of questionnaire collected was 139 , including 106 copies from internal audit workers and 33 from the audited objects. The missing values that appeared in the questionnaire survey were processed using SPSS and made up for by means.

The calculations applied AMOS20 software and the resulting standardized path model was shown in Fig .3, where figures at the top right of the observed variables represented their variances; figures between exogenous variables represented product-moment correlation coefficient between two variables, and figures over single arrow symbols represented path coefficients (standardized regression coefficients) of exogenous variables against endogenous variables.

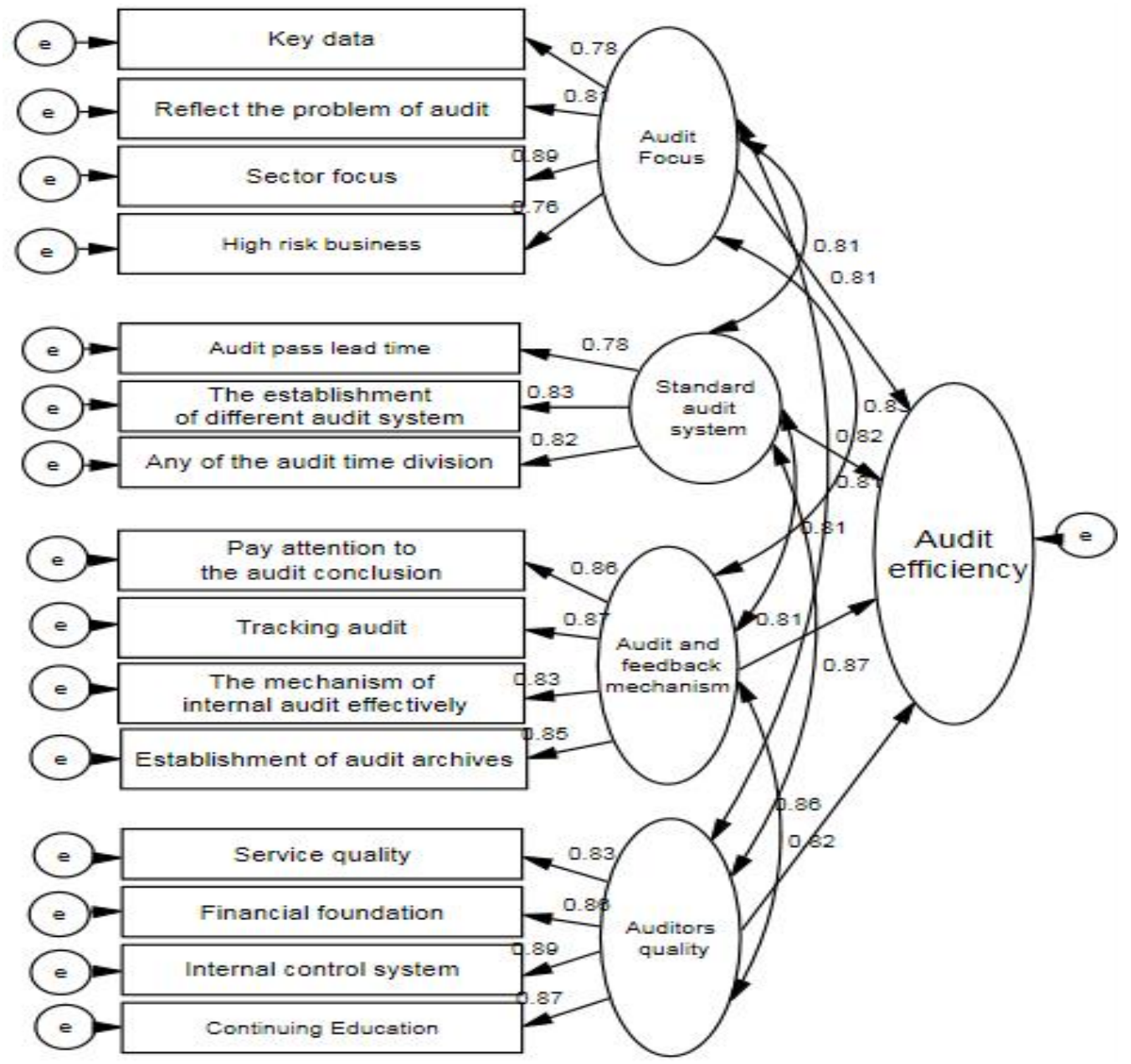

Figure 3.

\section{Analysis and Conclusions}

As can be seen from Figure 3, the four observed variables of audit focus showed higher path coefficients, especially the key data, indicating that whether to find the key data in the audit process can affect the efficiency of the audit.

In terms of audit feedback mechanism, its four observed variables, i.e. attention to audit findings, follow-up audit, effective internal audit mechanism, and establishing audit files showed higher path coefficients, especially the follow-up audit, indicating that work on these aspects needs to be improved in order to improve the efficiency of internal audit.

On auditors' qualities, the four observed variables including professional quality, financial basis, internal control system, and continuing education showed higher path coefficients, indicating that in order to improve the overall efficiency of the internal audit, it is of great help to improve staff quality of the four service links of internal audit, audit focus, audit feedback mechanism, and auditors' qualities showed significantly higher path coefficients than whether to have a standard audit system in economic responsibility audit, indicating that the priority should be given to upgrading the service 
capabilities in three aspects of audit focus, audit feedback mechanism and audit personnel's qualities.In summary, to improve audit efficiency the internal economic responsibility audit shall start from four aspects of audit focus, standard audit system, audit feedback mechanism, and auditors' professional quality.

\section{Acknowledgements}

Longdong University doctoral research start-up funding project (No.: XYBE1605)

\section{References}

[1] H. Ashbaugh, R. Lafond, B.W. Mayhew,Do non-audit services compromise auditor independence? Further evidence,Accounting Review, 78 (2003), pp. 611-639

[2] M. Barclay, R.H. Litzenberger,Announcement effects of new equity issues and the use of intraday price data,Journal of Financial Economics, 21 (1988), pp. 71-99

[3] Lixing, 'How to improve the Quality and Efficiency of Economic Audit on University leaders leaving',Journal of Longdong University,1,(2013),pp.99-101

[4] V.L. Bernard,Cross-sectional dependence and problems in inference in market-based accounting research,Journal of Accounting Research, 25 (1987), pp. 1-48

[5] P.K. Chaney, K.L. Philipich,Shredded reputation: the cost of audit failure,Journal of Accounting Research, 40 (2002), pp. 1221-1245

[6] C. Chow, The demand for external auditing: Size, debt, and ownership influences, The Accounting Review, 57 (1982), pp. 272-291

[7] L. DeAngelo,Auditor size and audit quality,Journal of Accounting and Economics, 3 (1981), pp. 183-200

[8] R. Dye,Auditing standards, legal liabilities, and auditor wealth,Journal of Political Economy, 101 (1993), pp. 887-914

[9] M. Jensen, The modern industrial revolution, exit, and the failure of internal control systems,Journal of Finance, 48 (1993), pp. 831-880

[10] Kinney,W, Z. Palmrose, S. Scholz, Auditor independence, non-audit services, and restatements: Was the US government right?,Journal of Accounting Research, 42 (2004), pp. 561-588

[11] Shu.S,Auditor resignations: clientele effects and legal liability,Journal of Accounting and Economics, 29 (2000), pp. 173-205

[12] Krishnan,J (Krishnan, J), Audit committee quality and internal control: An empirical analysis,80.2(2004),pp.649-675

[13] Neter, J; Kutner, MH; Nachtsheim, CJ; Wasserman, W.Applied linear statistical models : 1996

[14]Dechow, PM; Dichev, The quality of accruals and earnings: The role of accrual estimation errors,IDACCOUNTING REVIEW ,77 ,S ,2002,pp. 35-59 